\title{
Fibrous Pseudotumor of Paratestis Mimicking a Testicular Tumor
}

\author{
Jangbhadur Singh", Ather Hafiz, Mohsin Rasool, Harbinder Singh, Shaveeta Sharma and Shazia Bashir
}

\author{
SKIMS-MC Srinagar, Kashmir, India
}

\begin{abstract}
Fibrous pseudotumor is a rare entity involving the paratestis comprising about 6\%. These lesions are considered to represent a benign reactive process that chiefly affect young adults and mimic testicular tumors. We report a case of a 35 year old male who presented with a painless testicular mass since 2 year. This case is reported due to its extreme rarity and highlights the need to incorporate this rare tumor as a differential diagnosis in young adults with testicular mass.
\end{abstract}

Keywords: Benign, fibrous, paratestis, pseudotumor.

\section{INTRODUCTION}

Fibrous pseudotumors are the third most common type of paratesticular tumors after spermatic cord lipomas and epididymal adenomatoid tumors [1] and represent a benign reactive process of the paratesticular region. Various synonyms have been used for this relatively rare lesion including inflammatory pseudotumor, inflammatory myofibroblastic tumor and proliferative funiculitis [2]. Currently, the term inflammatory myofibroblastic tumor has been generally accepted. The peak incidence is usually in the third decade of life but can occur at any age [2].

\section{CASE REPORT}

A 35 year old male presented to our surgical outpatient department with a painless scrotal mass since 2 years. There was no previous surgical, traumatic or any other significant past history. Physical examination revealed multiple firm to hard irregular non-tender masses in the right scrotum ranging in size from $1 \mathrm{~cm}$ to $3 \mathrm{~cm}$ that did not transilluminate. The afetoprotein and the human chorionic gonadotropin levels were within normal limits. Ultrasound revealed a benign tumor mass. The provisional clinical diagnosis of right testicular tumor was made and a right orchidectomy was performed.

\section{PATHOLOGY}

We receieved a right orchidectomy specimen with testis measuring $8 \times 5 \times 3 \mathrm{~cm}$ and attached spermatic cord that measured $4 \times 1.5 \mathrm{~cm}$. Cut section revealed testis surrounded by multiple grey white nodules ranging in size from 1 to 3 $\mathrm{cm}$ (Fig. 1). Testis was grossly uninvolved by the tumor and separated by thickened tunica albuginea and tunica vaginalis. Microscopically, Testicular tissue appeared normal with seminiferous tubules showing spermatogenesis and mild thickening of the basement membrane. The tumor was paratesticular with no connection with the testis and was composed of dense fibrocollagenous stroma containing

*Address correspondence to this author at the SKIMS-MC Srinagar, Kashmir, India; Tel: +91 9419032757; E-mail: jangju@rediffmail.com chronic inflammatory infiltrate, myofibroblasts, thick walled blood vessels and dense collagen bands encasing the testis with testis showing maturation arrest (Fig. 2). No necrosis, mitotic activity, or cellular pleomorphism was present. Thus a histopathological diagnosis of inflammatory myofibroblastic tumor was made. We had a six month postoperative symptom free follow-up of the patient.

\section{DISCUSSION}

In 1904, Balloch [3] first described fibrous pseudotumor involving the paratestis. Paratesticular pseudotumors are relatively rare scrotal masses comprising approximately $6 \%$ of paratesticular lesions [2].

Although the etiology is largely unknown, these lesions are generally considered to represent a benign reactive proliferation of inflammatory and fibrous tissue, likely in response to trauma, infection, surgery, or inflammation [4]. Tunica vaginalis is most commonly affected $(75 \%)$, followed by epidiymis(10\%) and the remainder involving the spermatic cord or the tunica albuginea [5]. Some rare but paratesticular fibrous pseudotumors are rarely associated with testicular infarction [6], schistosomiasis, retroperitoneal fibrosis, Gorlin syndrome and HIV particularly the inflammatory variant [7].

Paratesticular fibrous pseudotumors usually presents as unilateral painless mass/masses mostly involving the left side [8] ranging in size from 0.5 to $8 \mathrm{~cm}$. The fibrous pseudotumors have non-specific appearances on ultrasonography. Diagnosis of the fibrous pseudotumor is difficult preoperatively due to non-specific features [2] and may even be confused with testicular tumor or chronic testicular infarction.

Macroscopically, these tumors present as single or multiple form, ovoid nodules and occasionally encasing the testes as diffuse band-like fibrosis. Microscopically, dense hyalinized collagen stroma with para-cellular fibroblastic or myofibroblastic activity and chronic inflammation, patchy granulation tissue, calcification, myxoid change or even ossification may be seen [9]. Testicular sparing surgeries are not possible in most of the cases especially in cases of 

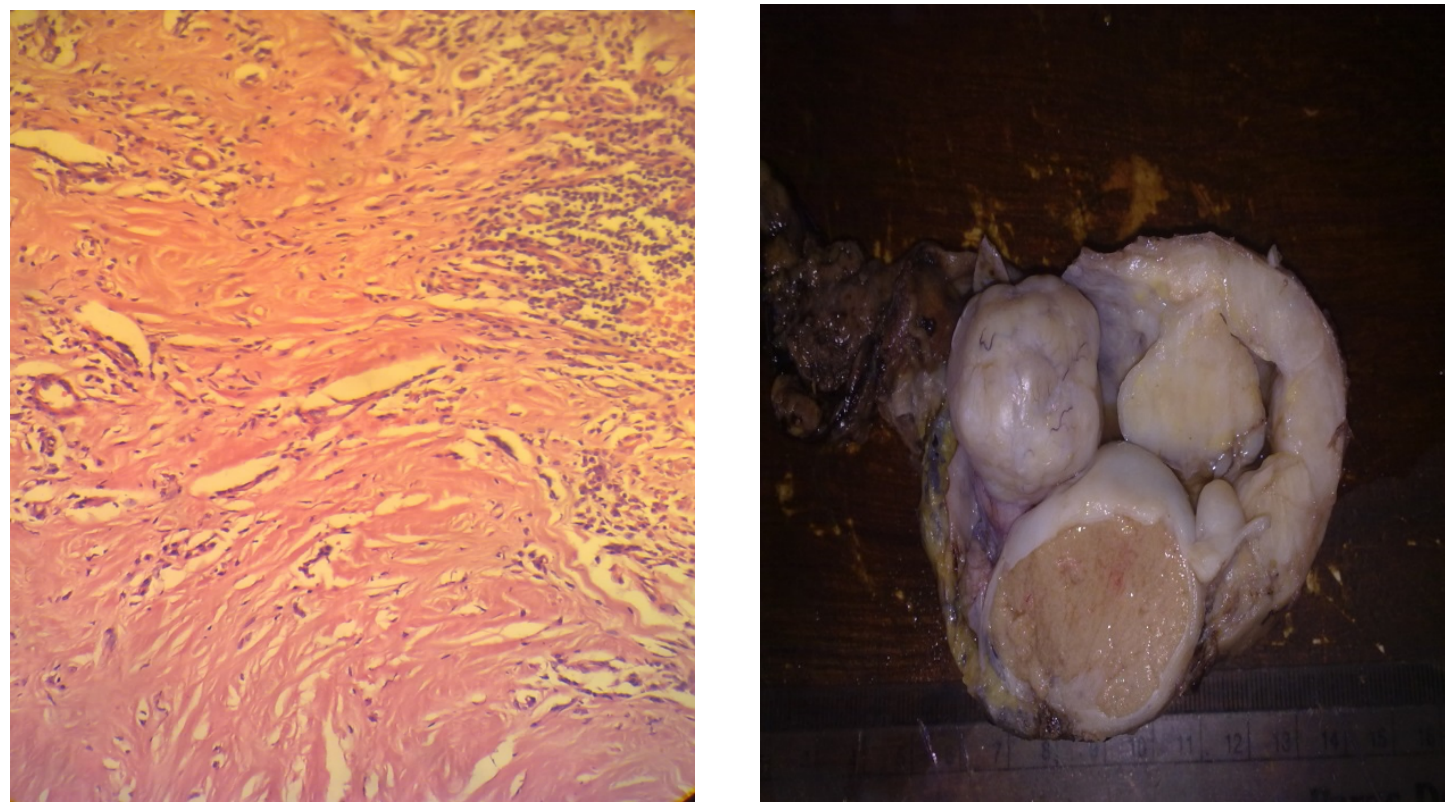

Fig. (1). Macroscopy shows testicular mass already cut open, Testis is grey yellow on cut section, many tumour nodules.
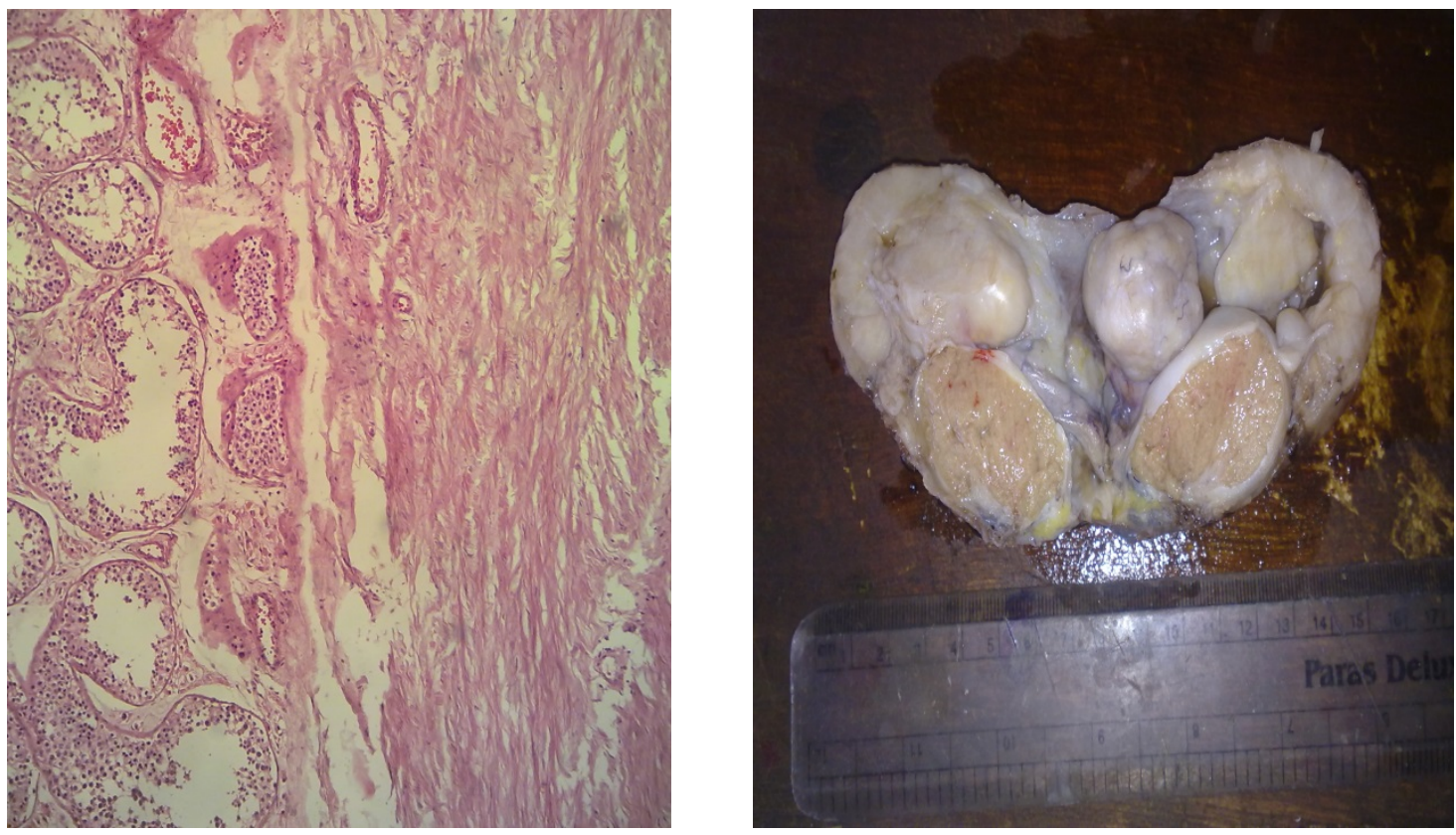

Fig. (2). Microscopy shows normal seminiferous tubules with spermatogenesis and diffuse fibrosis in the subjascent tissue, along with collections of chronic inflammatory cells.

fibromatous periorchitis. Treatment of choice is scrotal exploration of the mass and frozen section biopsy [10]. However, if testicular tumor cannot be excluded with certainty, radical orchidectomy is the procedure of choice.

\section{CONCLUSION}

Fibrous pseudotumors of the paratestis are relatively rare with a peak incidence in young adulthood. These tumors may be confused with testicular tumors and should be always included in the differential diagnosis in young adults with testicular and paratesticular lesions.

\section{CONFLICT OF INTEREST}

The authors confirm that this article content has no conflict of interest.

\section{ACKNOWLEDGEMENTS}

Declared none.

\section{REFERENCES}

[1] Ulbright TM, Amin MB, Young RH. Tumors of the testis, adnexa, spermatic cord and scrotum. In: Atlas of Tumor Pathology. $3^{\text {rd }}$ series. Fascicle 25. Washington, DC: Armed Forces Institute of Pathology 1997; pp. 315-9. 
[2] Ugras S, Yesil C. Fibrous pseudotumors of tunica albuginea, tunica vaginalis and epididymis: Report of two cases. Cancer Epidemiol 2009; 33: 69-71.

[3] Balloch E. Fibromata of the tunica vaginalis. Ann Surg 1904; 39: 396-9.

[4] Jones MA, Young RH, Scully R. Benign fibromatous tumors of the testis and paratesticular region: a report of 9 cases with a proposed classification of fibromatous tumors and tumor-like lesions. Am J Surg Pathol 1997; 21: 296-305.

[5] Woodward PJ, Schwab CM, Sesterhenn IA. From the archives of the AFIP: extratesticular scrotal masses-radiologic-pathologic correlation. Radiographics 2003; 23: 215-40.

[6] Seethala RR, Tirkes AT, Weinstein S, Tomaszewski JE, Malkowicz SB, Genega EM. Diffuse fibrous pseudotumor of the testicular tunics associated with an inflamed hydrocele. Arch Pathol Lab Med 2003; 127: 742-4.

[7] Navai N, Yap RL, Gupta R, Fraser TG, Gonzalez CM. Inflammatory pseudotumor of the testis: a novel presentation of acute retroviral syndrome. Int J Urol 2005; 12: 424-6.

[8] Germaine P, Simerman LP. Fibrous pseudotumor of the scrotum. J Ultrasound Med 2007; 26: 133-8.

[9] Olivia E, Young RH. Paratesticular tumor-like lesions. Semin Diagn Pathol 2000; 17: 340-58.

[10] Tobias-machado M, Corrêa LNA, Heloisa SL, Borrelli M, Wroclawski ER. Fibrous pseudotumor of tunica vaginalis and epididymis. Urology 2000; 56(4): 670-2.

(C) Singh et al.; Licensee Bentham Open.

This is an open access article licensed under the terms of the Creative Commons Attribution Non-Commercial License (http://creativecommons.org/licenses/by-nc/3.0/) which permits unrestricted, non-commercial use, distribution and reproduction in any medium, provided the work is properly cited. 